\title{
DESEMPENHO IN VITRO E AGRONÔMICO DE CULTIVARES MICROPROPAGADAS DE MORANGUEIRO EM VÁRIOS SUBCULTIVOS ${ }^{1}$
}

\author{
EUNICE OLIVEIRA CALVETE 2 , MAGALI FERRARI GRANDO 3 \\ DANIELE GUERREIRO GOMIDE ${ }^{4}$, RICARDO EOCLIDES MARAN ${ }^{5}$, MARILEI SUZIN ${ }^{6}$, \\ ALEXANDRE AUGUSTO NIENOW ${ }^{7}$, DILETA CECCHETTI ${ }^{8}$
}

RESUMO - O morangueiro é uma espécie multiplicada vegetativamente, o que facilita a progressão de viroses a partir de mudas infectadas. A utilização de matrizes provenientes do processo de cultivo in vitro tem sido uma prática na obtenção de mudas isentas de patógenos. Diversos protocolos de micropropagação recomendam a utilização de quatro subcultivos, para preservar a identidade genética dos clones e manter alta taxa de multiplicação. Desta forma, visando a elevar a eficiência do processo de micropropagação, foram utilizadas duas cultivares de morangueiro Oso Grande e Vila Nova, submetidas a nove subcultivos, sendo avaliadas a taxa de multiplicação e a variação somaclonal. Durante o cultivo in vitro, foi avaliada a taxa de multiplicação, a altura e o número de folhas por propágulo. Na aclimatização, determinaram-se a taxa de sobrevivência, a área foliar, a massa fresca e seca da parte aérea e da raiz. As mudas obtidas a partir de matrizes também foram avaliadas quanto ao comportamento agronômico, em ambiente protegido. A maior taxa de multiplicação foi observada durante o $2^{\circ}$ e o $3^{\circ}$ subcultivos com média de sete a oito propágulos/ explante, respectivamente. Não foram observadas alterações fenotípicas nas duas cultivares, durante as fases de micropropagação, aclimatização e crescimento em ambiente protegido. A cv. Oso Grande apresentou maior desempenho agronômico que a 'Vila Nova'.

Termos de indexação: Fragaria X ananassa Duch., variação somaclonal, taxa de multiplicação, micropropagação.

\section{AGRONOMIC AND IN VITRO PERFORMANCE OF MICROPROPAGATED STRAWBERRY CULTIVARS IN DIFFERENT NUMBERS OF SUBCULTURES}

\begin{abstract}
Strawberry is a vegetative propagated plant, what makes it easier for virus contamination through infected plantlets. The use of matrix plants generated by in vitro shoot apex cultivation has being useful to regenerate free pathogens plants. To preserve the genetic identity and to maintain the high multiplication rate, most micropropagation protocols are based on four subcultures. With the objective to elevate the efficiency of the micropropagation process, two strawberry cultivars (Oso Grande and Vila Nova) were submitted to nine subcultures, and it was evaluated the multiplication rate and the occurrence of somaclonal variation. While cultivated in vitro, it was evaluated the multiplication rate, plant height and number of leaves by propagule. At the acclimatization stage it was determined the survival rate, leaf area, aerial and root fresh and dry weight. The clones obtained from the matrix plants were evaluated in relation to the agronomic behavior during the fruit production stage in a protected environment. The highest in vitro multiplication rate was observed during the second and third subculture, with the average of seven to eight propagules per explants, respectively. It was not observed phenotypic alterations in the two cultivars during the micropropagation process, acclimatization and growth in a protected environment. The Oso Grande cultivar presented higher agronomic performance when compared to the Vila Nova cultivar.

Index terms: Fragaria $\mathrm{X}$ ananassa Duch., somaclonal variation, in vitro multiplication rate, micropropagation.

\footnotetext{
1(Trabalho 243-08).Recebido em: 26-09-2008. Aceito para publicaçãoem: 17-04-2009.

${ }^{2}$ Eng ${ }^{\mathrm{a}}$.-Agr ${ }^{\mathrm{a}}$., Dr ${ }^{\mathrm{a}}$., Profa. de Olericultura e Horticultura Geral da Faculdade de Agronomia Medicina Veterinária (FAMV) da Universidade de Passo Fundo (UPF), Campus I, Passo Fundo-RS, Cx. Postal 611, CEP 99001-970, calveteu@upf.br

${ }^{3}$ Bióloga, Ph.D. profa. de Genética e Biotecnologia da FAMV e ICB/UPF, magali@upf.br

${ }^{4} E_{n g}$.-Agra ., Mestre pelo Programa de Pós- Graduação em Agronomia - FAMV/UPF, dwgomide@dow.com

${ }^{5}$ Eng.-Agr., bolsista Fapergs, r.maran@bol.com.br

${ }^{6}$ Eng $^{\mathrm{a}}$-Agra ., Ms., Laboratório de Biotecnologia Vegetal da FAMV/UPF, suzin@upf.br

${ }^{7}$ Eng.-Agr., Dr., prof. de Fruticultura da FAMV/UPF, alexandre@upf.br

${ }^{8}$ Matemática, Ms., profa. de Estatística da UPF, cecchetti@upf.br
} 


\section{INTRODUÇÃO}

O morangueiro (Fragaria X ananassa Duch.) é uma espécie herbácea rasteira, propagada vegetativamente por meio de estolões. Em geral, a cultura é renovada anualmente, utilizando mudas isentas de vírus, oriundas de micropropagação (Daniels, 1984).

Para a limpeza clonal in vitro, os propágulos devem ser oriundos de meristemas, multiplicados pela técnica de micropropagação, que compreende: coleta do material vegetal, desinfestação e inoculação dos explantes em meio próprio para a regeneração das partes aéreas, com posterior multiplicação, enraizamento e aclimatização (Augustin et al., 2002). A fase de multiplicação caracteriza-se pela proliferação de brotos axilares ou adventícios em número variável, conforme o genótipo utilizado, determinando a capacidade deste em formar folhas e novos meristemas. Durante essa etapa, vários cuidados são necessários para manter a homogeneidade do cultivo, devendo ser levados em conta o número e os intervalos dos subcultivos, a taxa de multiplicação e a estabilidade genética do material, evitando a variação somaclonal. Sais minerais (Donnelly et al., 1984), níveis de benziladenina e o número de subcultivos (Rancillac \& Nourisseau, 1989) são alguns fatores que afetam a estabilidade do material obtido in vitro.

Os períodos de incubação entre os subcultivos, para a maioria das espécies, comumente são de quatro semanas. Em condições ideais de cultivo, multiplicações de cinco a dez vezes podem ser obtidas num período de quatro a oito meses (Mantell et al., 1994). Embora a maioria dos laboratórios utilize, para obter segurança em relação à identidade genética das mudas, protocolos de micropropagação com quatro ou cinco subcultivos, Boxus et al. (2000) sugerem limite de dez subcultivos para a micropropagação do morangueiro. Estudos realizados por Schwartz et al. (1981) não verificaram variações para a maioria das características agronômicas, micropropagando três cultivares de morangueiro em até seis subcultivos, com redução apenas do peso médio dos frutos por planta. Por outro lado, Arruda et al. (2006) identificaram variação somaclonal ao nível molecular mesmo a baixas concentrações de BAP (6- Benzilaminopurina), em um único subcultivo.

A última fase da micropropagação caracteriza-se pela aclimatização das plântulas. A saída do cultivo in vitro para o ex vitro resulta em mudanças abruptas no ambiente, podendo influenciar no crescimento e na qualidade do produto final (Debergh, 1991).

Variações fenotípicas em plantas regeneran- tes micropropagadas, avaliadas na fase de produção, têm sido pouco estudadas. Essas alterações referemse, principalmente, às características morfológicas, como ciclo da cultura, produção e cor de frutos, número de ramos primários, cor de flores e resistência a patógenos (Brunello, 2002). Plantas de morangueiro oriundas de micropropagação, tendo como explante inicial o ápice caulinar, têm originado, esporadicamente, frutos anormais (Schwartz et al., 1981). Kumar et al. (1999) não observaram alterações morfológicas a campo em plantas oriundas de quatro subcultivos in vitro, não apresentando diferenças moleculares por marcadores RAPD. Rancillac \& Nourisseau (1989) verificaram, no gênero Fragaria, que subcultivar ilimitadamente durante a fase de micropropagação pode propiciar crescimento desordenado das plantas no campo, como a ausência ou fragilidade de raízes, excessiva formação de flores, tamanho pequeno e/ ou frutos deformados, e plantas heterogêneas. Este trabalho teve por objetivos avaliar duas cultivares de morangueiro, submetidas a diferentes números de subcultivos, durante a micropropagação, aclimatização e no período de produção de frutos.

\section{MATERIAL E MÉTODOS}

O trabalho foi desenvolvido no Laboratório de Biotecnologia Vegetal e em ambiente protegido do Setor de Horticultura da FAMV/UPF, durante os anos de 2003 e 2004.

Cultivo in vitro - Nesta etapa, isolaram-se gemas apicais de morangueiro em câmara de fluxo laminar, transferindo-se essas para tubos de ensaio contendo meio MS (Murashige \& Skoog, 1962) suplementado com 1,0 $\mathrm{mg} \mathrm{L}^{-1}$ de benzilaminopurina (BAP), 1,0 $\mathrm{mg} \mathrm{L}^{-1}$ de ácido indolbutírico (AIB) e 1,0 $\mathrm{mg} \mathrm{L}^{-1}$ de ácido giberélico ( $\left.\mathrm{GA}_{3}\right)$, com adição de 30 $\mathrm{g} \mathrm{L}^{-1}$ de sacarose e $6 \mathrm{~g} \mathrm{~L}^{-1}$ de ágar. $\mathrm{O} \mathrm{pH}$ do meio de cultura foi ajustado para 5,8. Os tubos permaneceram no escuro, em ambiente com temperatura controlada $\left(25^{\circ} \mathrm{C}\right)$, por 72 horas (início da brotação), sendo, posteriormente, transferidos para luz (16 h luz/dia), nas mesmas condições de temperatura. Após 40 dias no meio de estabelecimento, as mudas foram transferidas para o meio de multiplicação (MS suplementado com $2 \mathrm{mg} \mathrm{L}^{-1}$ de BAP e 0,5 $\mathrm{mg} \mathrm{L}^{-1}$ de $\mathrm{GA}_{3}$ ) A cada 30 dias foram realizadas as repicagens até 0 décimo subcultivo.

Os tratamentos constaram de duas cultivares de morangueiro Vila Nova e Oso Grande, dispostos no delineamento experimental de blocos ao acaso, com parcelas subdivididas no tempo (subcultivos 2; 3; 4; 5; 6; 7; 8; 9 e 10). Cada parcela constou de cinco plantas por frasco, com sete repetições. Em cada 
subcultivo, foram avaliadas a taxa de multiplicação (número de propágulos/explante em cada subcultivo), número acumulado de propágulos obtidos na sequência dos subcultivos, número de folhas por propágulo e altura de brotações.

Para efeito de análise estatística, as médias das variáveis altura de plantas e número total de folhas por propágulo foram transformadas para raiz quadrada. Os dados foram submetidos à análise de variância, e as diferenças entre as médias foram comparadas pelo teste de Tukey, a 5\% de significância. A taxa de multiplicação foi comparada pelo teste não paramétrico de Kruskall-Wallis, a 5\% de significância.

Aclimatização das plantas micropropagadas - Foram utilizadas mudas enraizadas de duas cultivares de morangueiro Oso Grande e Vila Nova, oriundas do $2^{\circ}, 4^{\circ}, 6^{\circ}, 8^{\circ}$ e $10^{\circ}$ subcultivos, em meio MS acrescido de 0,005 $\mathrm{mg} \mathrm{L}^{-1}$ de BAP e 6,0 $\mathrm{g} \mathrm{L}^{-1}$ de ágar. $\mathrm{O}$ delineamento foi em blocos ao acaso, no esquema fatorial 2 (cultivares) x 5 (subcultivos), com três repetições e 12 plantas por parcela. As mudas foram transplantadas para bandejas de isopor de 72 células $\left(110 \mathrm{~cm}^{3}\right)$, contendo, como substrato, casca de arroz carbonizada (30\%), vermicomposto (25\%), solo mineral Latossolo Vermelho-Escuro (35\%) e vermiculita (10\%), e mantidas em estufa agrícola com sistema de nebulização intermitente, com molhamento a cada 12 minutos, por seis segundos.

Durante o período de aclimatização, foram efetuadas três aplicações de nutrientes e duas de fungicidas (Ridomil $3 \mathrm{~g} \mathrm{~L}^{-1}$ ). A solução nutritiva foi preparada à base dos componentes da soluçãoestoque do meio MS, citado por Caldas et al. (1998), nas quantidades de $4 \mathrm{~mL} \mathrm{~L}^{-1}$ da solução A; $5 \mathrm{~mL} \mathrm{~L}^{-1}$ das soluções B e C; $2 \mathrm{~mL} \mathrm{~L}^{-1}$ das soluções D e H; e $1 \mathrm{~mL} \mathrm{~L}{ }^{-1}$ das soluções E, F, e G. Antes da aplicação, diluiu-se a solução nutritiva na proporção de 1:5 (solução: água).

As avaliações foram realizadas após 60 dias do transplante, determinando as seguintes variáveis: taxa de sobrevivência (\%), massa fresca e seca da parte aérea e raízes (g) e área foliar $\left(\mathrm{cm}^{2}\right)$. A área foliar foi determinada através de um planímetro eletrônico portátil, modelo LI-3000 (LI- COR inc.). Os dados foram submetidos à análise de variância e de regressão.

Comportamento agronômico de cultivares micropropagadas em vários subcultivos - Os tratamentos foram constituídos de mudas das cultivares Oso Grande e Vila Nova, provenientes de 2; 4; 6; 8 e 10 subcultivos. O delineamento foi em blocos ao acaso, com os tratamentos arranjados no esquema fatorial $2 \times 5$, com quatro repetições e 12 plantas por parcela.

As matrizes das duas cultivares foram multiplicadas em telado. Em maio de 2004, mudas com três folhas definitivas, diâmetro da coroa medindo $8 \mathrm{~mm}$ e sistema radicular de $50 \mathrm{~mm}$ foram transplantadas no espaçamento de 0,3 x 0,3 m, para uma estufa agrícola de $10 \times 28 \mathrm{~m}$, coberta com plástico de polietileno de baixa densidade (PEBD) antiUV de 200 micras, disposta no sentido nordeste-sudeste. Após o estabelecimento das mudas, foi colocada uma cobertura sobre o solo, com plástico preto (mulching). A irrigação foi por gotejamento, com mangueiras fixas e gotejadores a cada $0,3 \mathrm{~m}$. Os controles fitossanitários foram realizados quando necessário, para oídio e ácaro-rajado.

As variáveis avaliadas foram número e massa fresca de frutos comerciais, para a indústria, deformados e totais por planta, de acordo com a classificação adotada pela CEAGESP (2002). Foi efetuada a análise de variância e comparadas as diferenças entre médias, pelo teste de Tukey, a 5\% de significância. Nos três experimentos, foi empregado o pacote estatístico SAS (Statistic Analysis System).

\section{RESULTADOS E DISCUSSÃO}

Cultivo in vitro - A maior média referente à taxa de multiplicação foi de sete propágulos/explante obtida na ‘Oso Grande’. Comportamento similar foi observado para 'Vila Nova', com média de oito propágulos/explante no segundo e terceiro subcultivos. Para ambas as cultivares, foram observadas reduções do número de propágulos produzidos após o terceiro subcultivo, atingindo médias de 1,6 e 1,7 propágulo/ explante nas cultivares Oso Grande e Vila Nova, respectivamente (Tabela 1). Os resultados foram superiores aos obtidos por Brham \& Oliveira (2004), com taxa de multiplicação, no terceiro subcultivo, de 4,1 e de 4,0 para as cvs. Oso Grande e Vila Nova, respectivamente.

Em relação ao número de propágulos acumulados, a cultivar Vila Nova apresentou, ao final de dez subcultivos, 32.760,ou seja, 2,6 vezes mais que o número de propágulos acumulados obtidos na cultivar Oso Grande, com 12.502 (Tabela1).

Um dos problemas práticos da aplicação de dez subcultivos é a obtenção tardia das matrizes e posterior formação das mudas, as quais seriam transplantadas para o campo em final do verão início do outono, quando as condições do ambiente de temperatura inferior a $15^{\circ} \mathrm{C}$ e fotoperíodo menor que 14 horas de luz não são favoráveis à produção de estolões. Na rotina do laboratório, os ápices cau- 
linares utilizados para iniciar o processo de micropropagação são retirados no início da primavera para evitar problemas oxidativos in vitro. Entretanto, se o número de subcultivos fosse elevado de quatro para seis, estima-se a obtenção de 735 e 2.004 propágulos das respectivas cultivares, sem prejudicar o cronograma posterior de multiplicação no viveiro, além de otimizar o processo de micropropagação.

Foi observada interação significativa entre as cultivares e o número de subcultivos para o variável número de folhas por propágulo. O maior número de folhas foi obtido na cultivar Vila Nova, no segundo e terceiro subcultivos, com média de 5,0 folhas/ propágulo. Em todos os subcultivos, a cultivar Vila Nova apresentou médias superiores à 'Oso Grande' (Tabela 2). Essa diminuição, provavelmente, reflete a redução do número de gemas adventícias formadas ao longo dos subcultivos, podendo ser esta, também, a causa da redução da taxa de multiplicação. Apenas no $2^{\circ}, 3^{\circ}, 4^{\circ}$ e $7^{\circ}$, subcultivos os explantes da cv. Vila Nova apresentaram maior número de folhas que a 'Oso Grande'. Independentemente da cultivar, foi observado que as folhas apresentaram desenvolvimento normal quanto à forma, tamanho e coloração. Assim, não foram identificadas variantes somaclonais in vitro quanto às características morfológicas.

Para a característica altura das brotações, houve efeito significativo dos tratamentos de forma independente, com maiores brotações na cv. Oso Grande $(1,2 \mathrm{~cm})$ que na cv. Vila Nova $(1,0 \mathrm{~cm})$. Também foi verificado redução na altura até o subcultivo seis, quando, então, passaram a ser obtidos maiores crescimentos (Tabela 2). Resultados contrários foram encontrados por Calvete et al. (2001), com a cv. Vila Nova apresentando maior desenvolvimento in vitro que a 'Oso Grande'.

Aclimatização - A taxa de sobrevivência durante a fase de aclimatização das plântulas oriundas dos cinco subcultivos não diferiu estatisticamente entre os tratamentos, variando de $88 \%$ a $98 \%$ para a cv. Vila Nova e de 72\% a 98\% para a cv. Oso Grande. Os resultados do presente estudo não concordam com aqueles obtidos por Pennell (1987), o qual relata que, quanto maior o número de subcultivos na micropropagação, menor será a taxa de sobrevivência em morangueiro.

Para as características de massa fresca e seca da parte aérea e raiz, não houve interação entre os tratamentos, entretanto as mesmas apresentaram significância de forma independente. A cv. Vila Nova apresentou maior massa seca da parte aérea e da raiz, com $0,16 \mathrm{~g}$ e $0,11 \mathrm{~g}$, respectivamente, enquanto a 'Oso Grande’ apresentou 0,13g e 0,09g.
Considerando a média das duas cultivares em cada subcultivo, verificou-se para a massa fresca da parte aérea e da raiz um comportamento quadrático semelhante (Figura 1a), demonstrando a estreita relação entre as partes, tendo sido superior em mudas provenientes do segundo subcultivo in vitro e diminuindo até o oitavo, com incremento quando obtidas do décimo subcultivo. Este resultado pode ser explicado pela alta taxa de multiplicação no segundo e terceiro subcultivos (cerca de sete), para ambas as cultivares, podendo as mudas terem utilizado grande parte da energia na emissão de novos brotos em detrimento do crescimento, e o aumento no décimo pode ser explicado pelo incremento da altura das brotações, verificado nesse subcultivo (Tabela 2). A variação da massa seca de parte aérea e raízes (Figura 1b) apresentou um padrão de comportamento semelhante ao da biomassa fresca.

A Figura 1c mostra a variação no comportamento da área foliar, considerando a média das duas cultivares, com comportamento quadrático, reduzindo nas mudas provenientes do quarto e do sexto subcultivos in vitro, apresentando as mudas do décimo subcultivo maior área foliar, com $25,75 \mathrm{~cm}^{2}$. Uma das prováveis explicações reside no fato de as plântulas do décimo subcultivo terem permanecido por maior período de tempo in vitro, ocasionando maior crescimento e desenvolvimento das folhas. Esse incremento observado na área foliar pode também explicar o comportamento das variáveis discutidas acima (Figura 1a , b).

Comportamento agronômico de cultivares micropropagadas em vários subcultivos - Não foram observados efeitos dos subcultivos sobre as características número e massa fresca dos frutos (Tabela 3). A cv. Oso Grande produziu maior número total de frutos por planta (35,9 frutos) e de frutos comerciais (23,8 frutos), não diferindo da cv. Vila Nova quanto ao número de frutos classificados para a indústria e deformados.

A massa fresca total e de frutos comerciáveis também foi superior na cv. Oso Grande, não diferindo da cv. Vila Nova quanto à produção de frutos destinados à indústria. Pagot \& Hoffmann (2003) relatam que, no Rio Grande do Sul, a produtividade média do morangueiro é de 300 a 400 gramas de frutos por planta. Entretanto, estudos realizados por Calvete et al. (2008) mostram que a cv. Oso Grande apresenta potencial de produção em torno de $600 \mathrm{~g} \mathrm{planta}^{-1}$, em condições de ambiente protegido.

No presente trabalho, não foram evidenciadas, nas duas cultivares de morangueiro, alterações fenotípicas durante o processo de cultivo in vitro, aclimatização e produção em ambiente protegido, 
mesmo utilizando dez subcultivos. Silvarolla (1992) afirma que, durante a micropropagação, a variabilidade possa ser induzida pelo genótipo, tipo de explante, tempo e número de subcultivos, uso dos fitormônios e a composição do meio. Rancillac \& Nourisseau (1989) também não verificaram mudanças em mudas de morangueiro avaliando o comportamento a campo de mudas oriundas de quatro e 19 subcultivos.

Por sua vez, com base em outros trabalhos, Boxus (1989; 2000) limitou a propagação do morangueiro em dez subcultivos, verificando que o aumento de subcultivos provoca instabilidade genética e epigenética. Rancillac \& Nourisseau (1989) relataram que ilimitados subcultivos em Fragaria resultam em crescimento desordenado a campo, fragilidade de raízes, excessiva formação de flores, frutos pequenos ou deformados e plantas heterogêneas. Por outro lado, após seis subcultivos, foram obtidas plantas com características superiores à testemunha.

Schwartz et al. (1981) observaram que plantas micropropagadas de três cultivares de morangueiro, após seis subcultivos, mostraram-se superiores em condição de campo quanto ao vigor, produção de estolões, comprimento do pecíolo, número de flores e número e peso de frutos por área, comparadas com as plantas-testemunha. No entanto, o peso médio do fruto por planta foi reduzido.

Não foram observadas diferenças na porcentagem de frutos deformados durante dez subcultivos. A deformação dos frutos está relacionada com vários fatores, como baixa temperatura, ausência de radiação, excesso de umidade relativa do ar, polinização deficiente, viabilidade do pólen e características da cultivar (Verdier citado por Medina, 2003). Medina et al. (2007) compararam duas cultivares de morangueiro multiplicadas sob três condições (micropropagadas, criopreservadas e pelo método convencional) quanto à produção e qualidade dos frutos. Observaram que a cv. Andana apresentou maior número de frutos pequenos e de segunda classe, não ocorrendo diferenças fenotípicas a campo.

TABELA 1 - Taxa de multiplicação e número de propágulos obtidos por ápice caulinar em dez subcultivos in vitro de duas cultivares de morangueiro. Passo Fundo-RS, FAMV/UPF, 2003.

\begin{tabular}{lcccccccccc}
\hline & \multicolumn{8}{c}{ Taxa de multiplicação $\left(\mathrm{n}^{\circ}\right.$ propágulos por explante) } \\
\cline { 2 - 11 } Cultivares & $\mathbf{2}$ & $\mathbf{3}$ & $\mathbf{4}$ & $\mathbf{5}$ & $\mathbf{6}$ & $\mathbf{7}$ & $\mathbf{8}$ & $\mathbf{9}$ & $\mathbf{1 0}$ & Média \\
\hline Oso Grande & $7 \mathrm{a}$ & $7 \mathrm{a}$ & $2 \mathrm{~b}$ & $3 \mathrm{ab}$ & $2,5 \mathrm{ab}$ & $2,7 \mathrm{ab}$ & $2,1 \mathrm{~b}$ & $2 \mathrm{~b}$ & $1,6 \mathrm{~b}$ & 3,3 \\
Vila Nova & $8 \mathrm{a}$ & $8 \mathrm{a}$ & $4,5 \mathrm{ab}$ & $2,4 \mathrm{bc}$ & $2,9 \mathrm{abc}$ & $2,3 \mathrm{bc}$ & $2,2 \mathrm{bc}$ & $1,9 \mathrm{bc}$ & $1,7 \mathrm{c}$ & 3,8 \\
\hline \multicolumn{10}{c}{ Número } & acumulado estimado de propágulos por explante \\
\hline Oso Grande & 7 & 49 & 98 & 294 & 735 & 1.985 & 4.167 & 8.335 & 12.502 & - \\
Vila Nova & 8 & 64 & 288 & 691 & 2.004 & 4.610 & 10.142 & 19.270 & 32.760 & - \\
\hline
\end{tabular}

Médias seguidas de mesma letra na linha não diferem entre si, pelo teste de Kruskall-Wallis, a 5\% de significância.

TABELA2 - Número de folhas por propágulo nos diferentes subcultivos in vitro das cultivares de morangueiro Vila Nova e Oso Grande. Passo Fundo-RS, FAMV/UPF, 2003.

\begin{tabular}{cccc}
\hline \multirow{2}{*}{ Subcultivos } & \multicolumn{2}{c}{ Número de folhas por propágulo } & \multirow{2}{*}{$\begin{array}{c}\text { Altura das } \\
\text { brotações (cm) }\end{array}$} \\
\cline { 2 - 3 } & \multicolumn{2}{c}{ Cultivares } & \\
\hline $\mathbf{2}$ & A $5,0 \mathrm{a}$ & B $4,3 \mathrm{a}$ & $1,24 \mathrm{ab}$ \\
$\mathbf{3}$ & A 5,0 a & B 4,3 a & $1,25 \mathrm{ab}$ \\
$\mathbf{4}$ & A 4,1 b & B 2,6 c & $0,86 \mathrm{c}$ \\
$\mathbf{5}$ & A 3,0 c & A 2,8 bc & $1,03 \mathrm{abc}$ \\
$\mathbf{6}$ & A 3,5 bc & A 3,3 b & $0,96 \mathrm{bc}$ \\
$\mathbf{7}$ & A 3,5 c & B 3,0 bc & $0,98 \mathrm{bc}$ \\
$\mathbf{8}$ & A 3,1 c & A 3,0 bc & $1,24 \mathrm{ab}$ \\
$\mathbf{9}$ & A 3,2 c & A 2,9 bc & $1,40 \mathrm{a}$ \\
$\mathbf{1 0}$ & A 2,9 c & A 2,6 bc & $1,21 \mathrm{abc}$ \\
\hline Média & 3,5 & 3,1 & 1,11 \\
\hline CV (\%) & 13,09 & 15,79 & 28,10 \\
\hline
\end{tabular}

Médias antecedidas de mesma letra maiúscula na linha e seguidas de mesma letra minúscula na coluna não diferem entre si, pelo teste de Tukey, a 5\% de significância. 
TABELA 3 - Comportamento agronômico dos frutos em duas cultivares de morangueiro, durante o ciclo produtivo. Passo Fundo-RS, FAMV/UPF, 2004.

\begin{tabular}{lcccc}
\hline \multirow{1}{*}{ Cultivares } & \multicolumn{4}{c}{ Número de frutos por planta } \\
\cline { 2 - 5 } & Total & Comercial & Indústria & Deformados \\
\hline Oso Grande & $35,9 \mathrm{a}$ & $23,8 \mathrm{a}$ & $12,2^{\mathrm{ns}}$ & $11,0 \mathrm{~ns}$ \\
Vila Nova & $28,7 \mathrm{~b}$ & $17,1 \mathrm{~b}$ & 11,6 & 9,8 \\
\hline CV (\%) & 17,51 & 14,94 & 28,97 & 19,89 \\
\hline Cultivares & \multicolumn{5}{c}{ Massa fresca de frutos por planta $(\mathbf{g})$} \\
\hline Oso Grande & $333,1 \mathrm{a}$ & $281,5 \mathrm{a}$ & $49,9^{\mathrm{ns}}$ & - \\
Vila Nova & $220,8 \mathrm{~b}$ & $176,6 \mathrm{~b}$ & 44,6 & - \\
\hline CV (\%) & 14,09 & 16,48 & 31,92 & - \\
\hline
\end{tabular}

Médias seguidas de mesma letra na coluna não diferem entre si, pela análise de variância.
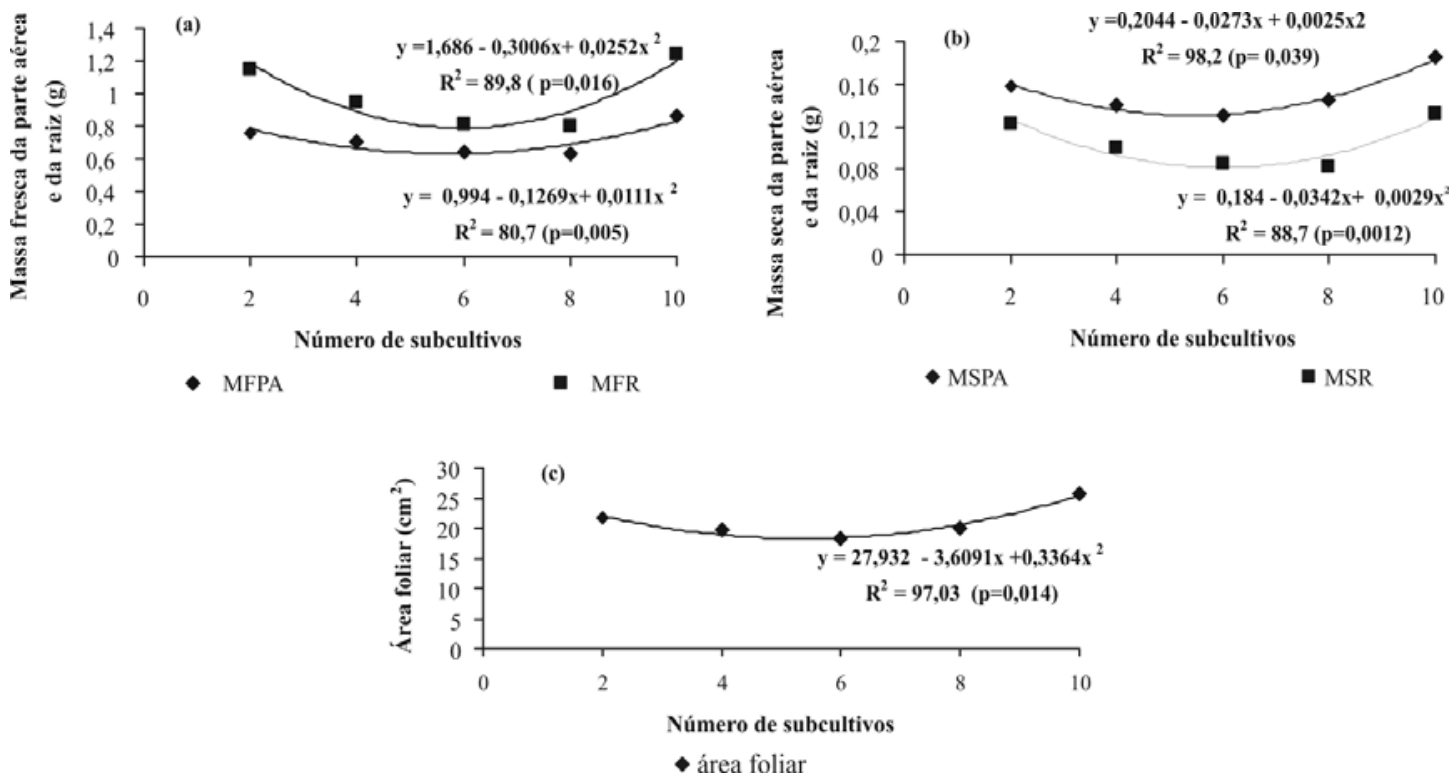

FIGURA 1 - Efeito dos subcultivos sobre a massa fresca (a) e seca (b) da parte aérea e radicular, e área foliar (c) de mudas de morangueiro cvs. Vila Nova e Oso Grande, na fase de aclimatização. Passo Fundo-RS, FAMV/UPF, 2003.

\section{CONCLUSÕES}

1-As maiores taxas de multiplicação in vitro das cultivares de morangueiro Oso Grande e Vila Nova são obtidas com dois e três subcultivos.

2-Não se evidenciam alterações fenotípicas mesmo com dez subcultivos durante o processo de micropropagação, aclimatização e período de produção de frutos em ambiente protegido.

3-A cultivar Oso Grande apresenta desempenho agronômico superior a Vila Nova no cultivo em ambiente protegido.

\section{REFERÊNCIAS}

ARRUDA, A. da SILVA; FIGUEIRA, E.R.; SILVA, A.S.; LONDE, L.N.; SOUZA, G. de F.M.V.; SPINI, V.B.M.G.; SOUZA, C.S.; KERR, W.E. Variação genômica intraclonal de explantes de morango em ambiente controlado. Bioscience Journal, Uberlândia, v.22, n.1, p.119-124, 2006.

AUGUSTIN, L.; CALVETE, E.O.; GRANDO, M.F.; SUZIN, M. Micropropagação vegetal e sua importância econômica. In: BRAMMER, S.P.; IORCZESKI, E. (Eds.). Atualização em técnicas celulares e moleculares aplicadas ao melhoramento genético vegetal. Passo Fundo: Embrapa Trigo, 2002. p. 135-153. 
BRHAM, R.U.; OLIVEIRA, R.P. Potencial de multiplicação in vitro de cultivares de morangueiro. Revista Brasileira de Fruticultura, Jaboticabal, v.26, n.3, p.507-510, 2004.

BRUNELLO, A.E.M. Clonagem: variação somaclonal em frutíferas perenes. Disponível em: < http:// www.ufv.br/dbg/BIO240/C017.htm. Acesso em: 8 out. 2002.

BOXUS, P. Review on strawberry mass propagation. Acta Horticulturae, Wageningen, v.265, p.309-320, 1989.

BOXUS, P.; JEMMALI, A.; TERZI, J.M.; AREZKI, O. Drift in genetic stability in micropropagation: the case of the strawberry. Acta Horticulture, Wageningen, v. 530, p. 155-162, 2000.

CALDAS, A.C.; HARIDASAN, P.; FERREIRA, M.E. Meios nutritivos. In: TORRES, A. C.; CALDAS, L.S; BUSO, J.A. (Eds.). Cultura de tecidos e transformação genética de plantas. Brasília: Embrapa-SPI/Embrapa - CNPH, 1998. p.87-132.

CALVETE, E.O.; SUZIN, M.; KRYZANSKI, A. Multiplicação in vitro de dois genótipos de morangueiro. Horticultura Brasileira, Brasília, v. 19, n.2, 2001. Suplemento. CD-ROM.

CALVETE, E.O.; MARIANI, F.; WESP, C. DE L.; NIENOW, A.A.; CASTILHOS, T.; CECCHETTI, D. Fenologia, produção e teor de antocianinas de cultivares de morangueiro em ambiente protegido. Revista Brasileira de Fruticultura, Jaboticabal, v.30, n.2, p.396-401,2008.

CEAGESP. Normas de classificação do morango. São Paulo: CQH/CEAGESP, 2002. 6p.

DANIELS, J.; ASSIS, M.; FONCECA, V.O.; LEAL, M.L. Produtividade de morango (Fragaria X ananassa Duch.) livre de vírus em solos tratados com fumigantes. Fitopatologia Brasileira, Brasília, v. 9, p. 15-20, 1984.

DEBERGH, P.C. Aclimatization techniques of plants from in vitro. Acta Horticulture, Wageningen, v.289, p. 291-300, 1991.

DONNELLY, D.J.; STACE-SMITH, R.; MELLOR, F.C. In vitro culture of three Rubus species. Acta Horticulture, Wageningen, v. 112, p. 69-75, 1984.
KUMAR, M.B.; BARKER, R.E.; REED, B.M. Morphological and molecular analysis of genetic stability in micropropagated Fragaria x ananassa cv. Pocahontas. In vitro Cellular \& Developmental Biology - Plant, Berlin, n. 35, p.254-258, 1999.

MANTELL, S.H.; MATTHEWS, J.A.; Mc KEE, R.A. Princípios da biotecnologia em plantas: uma introdução à engenharia genética em plantas. Ribeirão Preto: Sociedade Brasileira de Genética, 1994. 344p.

MEDINA, J.J.; CLAVERO-RAMÍREZ, I.; GONZÁLEZ - BENITO, M.E.; GÁLVEZ-FARFÁN,J.; LÓPEZ-ARANDA, J.M.; SORIA, C. Field perfomance characterization of strawberry (Fragaria $\mathrm{X}$ ananassa Duch.) plants derived from cryopreserved apices. Scientia Horticulturae, Amsterdam, v.113, n.1, p.28-32, 2007.

MEDINA, J.L. Análisis y evolución agronômica de lãs deformaciones de fruto em fresa. Posibles soluciones. In: JORNADAS AGRÍCOLAS Y COMERCIALES DE EL MONTE, 20., 2003, Huelva, Espanha. Anais... Huelva: Caja Rural, 2003. p.101-115.

MURASHIG E,T.; SKOOG, F. A revised medium for rapid growth and bioassays with tabacco tissue cultures. Physiologia Plantarum, Copenhagen,v. 15, n.3, p.473-497, 1962.

PAGOT, E.; HOFFMANN, A. Produção de Pequenas Frutas. In: SEMINÁRIO BRASILEIRO SOBRE PEQUENAS FRUTAS, 1.,2003, Vacaria. Anais... Vacaria: Embrapa Uva e Vinho, 2003. p. 9-17.

PENNELL, D. Strawberry micropropagation within the UK. In: BOXUS, P.; LARVOR, P. (Eds.). In vitro culture of strawberry plants. Bruseels: Commission of the European Communities, p.27-34, 1987 (Report EUR 10781 EN-ER).

RANCILLAC, M.J.; NOURRISEAU, J.G. Micropropagation and strawberry plant quality. Acta Horticulturae, Wageningen , v. 265, p.343-348, 1989.

SCHWARTZ, H.J.; GALLETA, G.J.; ZIMMERMAN, R.H. Field perfomance and phenotypic stability of tissue culture - propagated strawberries. Journal of the American Society Horticulture Science, Alexandria, n. 106, p. 667-73, 1981.

SILVAROLLA, M.B. Plant genomic alterations due to tissue culture. Journal Brazil Association Advance Science, São Paulo, v.44, p. 329-335, 1992. 